\title{
Study on construction site Safety Management from the perspective of learning organization theory
}

\author{
Shi Fazhong ${ }^{1 a^{*}}$, Shi Wenyin ${ }^{2}$ \\ ${ }^{1}$ Qinghai special education school, Qinghai University, Xining, Qinghai Province, 810016, China \\ ${ }^{2}$ Chengbei District MaFang construction company, Qinghai University, Xining, Qinghai Province, 810016, China
}

\begin{abstract}
Safety is the basis of all production and living behaviors, and is an important guarantee for the safety of employees' lives and enterprises' property. This study focuses on the construction site safety management as the research object, and analyzes the current situation and shortcomings of the construction site safety management. This paper tries to explain the deep causes of the current situation by the theory of learning organization, and gives some suggestions to further improve the safety management of the construction site.
\end{abstract}

\section{INTRODUCTION}

Safety is the guarantee of maintaining social stability and economic development, and the premise of maintaining the normal production activities of enterprises and the normal life of employees. "Safety first" is the respect for the right of life, which embodies the moral principle of life first. From a macro point of view, construction site safety management is related to social stability and the steady development of national construction. From the micro level, safety management is related to the sustainable and stable development of a construction enterprise, the life safety of every employee, the development of their body and mind and their whole life, and the happiness of every family.

\section{RESEARCH BACKGROUND}

\subsection{The construction site safety management regulations are constantly strengthened at present}

The state attaches great importance to safety in production, has issued and constantly updated the relevant regulations on safety management of construction site, and has macroscopically stipulated the contents of safety management of engineering construction, safety management of construction units, fire safety management of construction site, emergency rescue and investigation of production safety accidents. And the on-site safety management is refined: for example, the requirements of "ten clean, neat and clean" on the construction site, the requirements of the general construction plan and system signs on the construction site, fire safety, etc.

At present, the safety management of construction site basically depends on the linear management thinking of standard formulation, enforcement, inspection and supervision. There are two directions for the research on strengthening the safety management of the construction site. One is to further refine the classification and strengthen the implementation from the laws and standards, and the other is to combine the modern and contemporary advanced monitoring and communication technology to develop the intelligent direction of the safety management of the construction site. For example, Wang Kecheng, Lu Junchao, Shen Yuxin and Tian $\mathrm{Ye}^{[1]}$ applied the concept of smart construction site to discuss the application of information technology to build an intelligent safety supervision mode to prevent safety accidents. Zhang kebing ${ }^{[2]}$ of Zhejiang University tried to establish the safety visual identification system and safety evaluation index system of residential construction site by using the analytic hierarchy process and fuzzy comprehensive evaluation technology of system engineering.

\subsection{The importance of systematic thinking}

Although through detailed safety regulations, constantly refining the site safety management standards, can theoretically prevent and eliminate safety accidents. But the construction site safety management as a system, the work site safety management as a process work, has the characteristics of a slow gradual process, this kind of system characteristics is not easy to detect, in addition, the mutual enhancement of non-linear inhibition in the whole interaction of management activities further reduces the management effectiveness. Because the person who solves the first problem in the system,is often not the same person who takes on the new problem. The causes and consequences are not connected in time and space. The dynamic complexity of a construction site

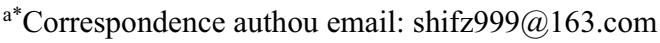


safety management system is described by a systems approach, as shown in figure 1. In a linear management model, safety requirements are generally assessed against safety standards because safety measures tend to go down as the rate of accidents goes down, which in turn leads to an increase in the rate of accidents, reaction said. When the safety accident rate increases, the task increases, and the quality of work decreases or the vulnerability increases through the time delay and system complexity, which leads to the decrease of safety management capability, resulting in a further increase in the safety accident rate. So constantly improve the assessment standards, constantly urge subordinates to implement, and the underlying problem is still not improved or even worse, this is the result of "non-systematic thinking" management. The first step to improving on-site safety management is to move away from linear thinking to systems thinking as a whole.

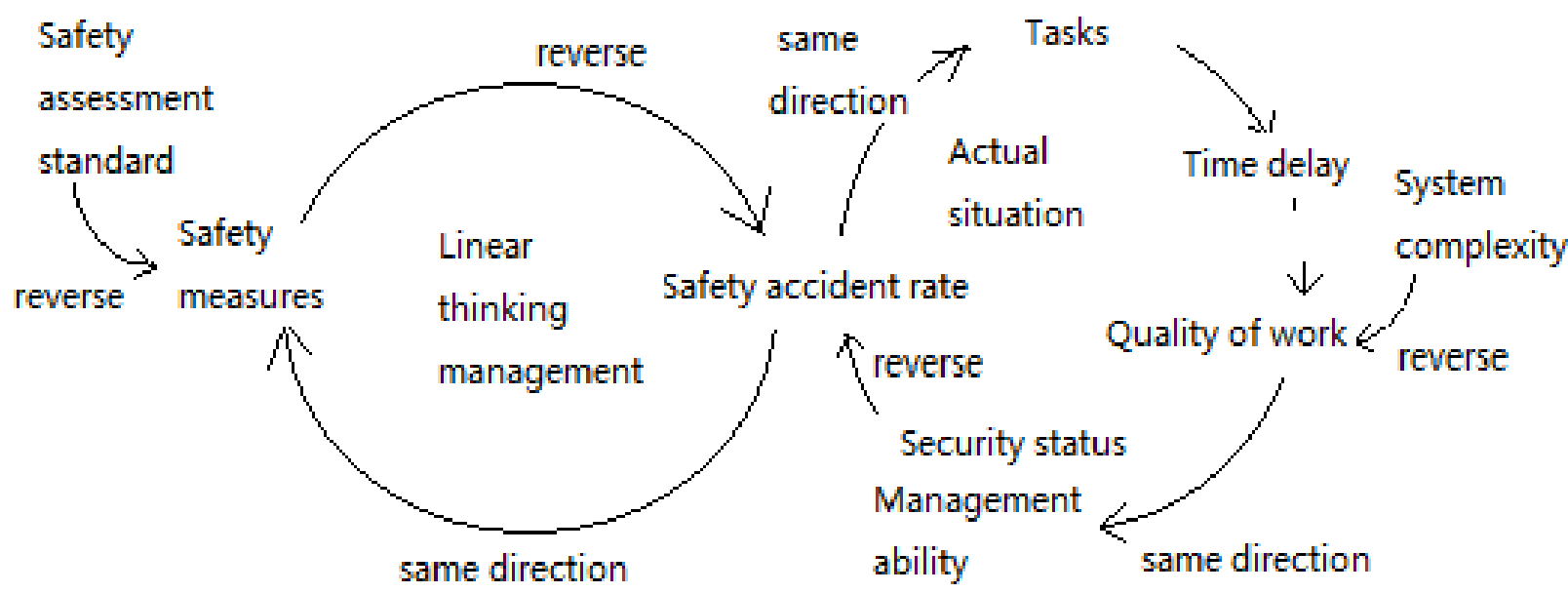

Figure1 Dynamic and complex characteristics of safety management system

It is an inevitable law for its objective development to improve it in the way of systematic thinking. We must enhance the safety management of construction site from the perspective of strengthening system thinking. On the other hand, whether it is to refine and strengthen the regulations and standards of construction site safety management, or to further enhance the intelligent high-tech content of site safety management, it is only to continuously improve the supervision and technical facilities objectively, without really paying attention to the ultimate core of safety management, that is, people's subjective initiative, and the real source of dangerous behavior, that is, people's safety awareness. Therefore, it is imperative to make a breakthrough in safety management thinking, considering not only the system characteristics of safety management on construction site, but also the integration of human safety subjectivity.

\section{INNOVATION OF SAFETY MANAGEMENT IN CONSTRUCTION SITE}

\subsection{Integrating and improving the safety management mechanism of construction site with learning organization theory}

In the face of development, the managers of various industries have tried various management theories, but with the one-sided common vision of various stages and static mechanized self transcendence, they can not solve the problem of dynamic and complex characteristics of the system. Most people gradually turn their attention to the learning organization theory, which is rooted in the common vision established on the basis of respecting personal development and in the innovation On the basis of the development of creative group communication ability and the systematic thinking of the overall interaction, it has profound and revolutionary reference significance for the management work in any field. It also has reference significance for the construction site safety management. Learning organization theory is a kind of macro management theory applicable to various organizations. Dr. St. Peterson's ${ }^{[3]}$ creativity is to enable all the staff to participate in organizational learning and continuous growth through organizational life. He called it "an organization that can try to make people from all walks of life fully engaged and capable of continuous learning.". After half a century of application, learning organization theory has developed a set of theoretical framework, which not only has a complete management theoretical system, but also has developed practical practice steps, so that individuals and groups have the ability to see the overall situation, surpass themselves, and think systematically, so as to fundamentally solve the dynamic and complex problems of site safety management system.

How to effectively unify the "subjective initiative" of all the people related to the site safety management into a goal, the learning organization gives the answer and implementation steps, so it is particularly urgent and important to investigate and analyze the current situation of the construction site safety management through the learning organization theory, and put forward the optimization path reference. 


\subsection{Integrating learning organization theory into site safety management}

Managers at all levels of the construction site need to use systematic thinking language to describe various on-site safety management problems, treat on-site safety management with a research attitude, and more importantly, let all departments and individuals participating in the learning organization of on-site safety management have more scientific and efficient management methods. This is the core of building an on-site safety management organization ${ }^{[4]}$. We must Train the site safety management learning organization. The organization establishes a common safety goal, that is, the integration of a common vision, which helps the organization cultivate each site construction personnel to actively and sincerely contribute and invest, rather than passively comply with. The deep-seated reason is that the realization of the common vision is not only the work activity itself, but also the motivation of people. In order to establish a common vision of site safety, the first step is to establish a common vision of on-site safety management based on systematic thinking, humanism and full participation. Secondly, the role of site managers as designers and teachers is more important in the whole process of leading the common vision. Promote the self transcendence of every employee. Only by constantly surpassing the limitation of safety consciousness and safety ability can we approach the ultimate goal of individual development. This is also the thinking mode of establishing the learning organization of on-site safety management. To change the working mode of on-site safety management, we need to change our own thinking mode first. We should turn our research and observation to the realistic level of our own safety awareness and skills. We should start from the system instead of starting from the point. We should not observe in line, but think in loop. This is also the psychological mechanism of establishing the learning organization of site safety management. Once a good safety management learning organization construction mechanism is established, the collective wisdom is often higher than the individual, and the collective has the action ability of the overall collocation. When the collective is really learning, not only does the collective produce excellent results, but individual members grow faster than other learning methods. This is also the team foundation for establishing a learning organization of site safety management.

\section{CONCLUSION, SUGGESTION AND PROSPECT}

Construction site safety management ${ }^{4}$ itself is a system with complex characteristics. Only by using systematic methods to understand and master its development law, can we effectively manage all aspects of site safety in a real sense.

It is not only a reasonable and appropriate exploration, but also a development direction of construction site management to apply the learning organization theory to the construction site safety management which involves a wide range, high degree of concern and great responsibility.

With the continuous development of the global economy, the application of learning organization management mode in the construction and manufacturing industry construction site safety management will have important theoretical and practical significance.

\section{REFERENCE}

1. Wang,K.C., Lu,J.C., Shen,Y.X., Tian,Y. (2019)Safety management of construction site based on "smart construction site". Science and technology horizon. Issue 6. pp.:37-39.

2. Zhang,K.B.(2005)Research on safety management system of residential construction site. ZheJiang University. pp.6:1-3.

3. Peter,S.(1998). The Fifth Discipline: Art and practice of learning organization. Shanghai SanLian Publishing, Translated by Guo,J.L., reviewed by Yang,S.Y. Cambridge City.pp.110-115.

4. Sun Zhijian,Liu mingxin. (2014) Management Science (Fifth Edition). Dalian :Dongbei University of Financial and Economics Press, pp. 210-215. 